\title{
Adsorptive Capacity of Activated Charcoal for Rifampicin with and without Sodium Chloride and Sodium Citrate
}

\author{
Orish Ebere Orisakwe, ${ }^{* a}$ Onyenmechi Johnson Afonne, ${ }^{a}$ Patrick U. Agbasi, ${ }^{a}$ Ndidi A. Ilondu, ${ }^{a}$ \\ Sabinus I. Ofoefule, ${ }^{b}$ and Ejeatuluchukwu OBI ${ }^{a}$ \\ Biokinetic Research Group, Toxicology Unit, Department of Pharmacology, College of Health Sciences, Nnamdi Azikiwe \\ University, ${ }^{a}$ Nnewi Campus, P. M. B. 5001, Nnewi, Anambra State, Nigeria and Department of Pharmaceutical Technology, \\ Faculty of Pharmacy, University of Nigeria, ${ }^{b}$ Nsukka, Enugu State, Nigeria. \\ Received October 23, 2000; accepted December 25, 2000
}

\begin{abstract}
The effects of two saline cathartics (sodium chloride and sodium citrate) on the adsorptive capacity of activated charcoal (AC) for rifampicin were studied. Solutions of rifampicin alone and rifampicin with $7.5 \mathrm{mg} / \mathrm{ml}$ cathartic solution were vortex-mixed for $30 \mathrm{~s}$ with different quantities of $\mathrm{AC}$. These were incubated for $30 \mathrm{~min}$ at $37^{\circ} \mathrm{C}$ and analyzed for free rifampicin spectrophotometrically at $320 \mathrm{~nm}$. The addition of sodium citrate significantly increased $(p<0.05)$ the adsorptive capacity of $\mathrm{AC}$ for rifampicin with a resulting decrease in B-50 values at both the therapeutic and simulated toxic doses. Sodium chloride addition reduced the binding of rifampicin to AC at the toxic doses. The adsorption of rifampicin to activated charcoal, both alone and with the two saline cathartics, obeyed quantity-dependent kinetics. AC may be co-administered with sodium citrate in the management of rifampicin overdose.
\end{abstract}

Key words activated charcoal; rifampicin; B-50 value; adsorption capacity; cathartic

The ability of activated charcoal (AC) to adsorb toxicologically important agents in the gastrointestinal tract, and thus prevent their adsorption, has been acknowledged for over a century. ${ }^{1)}$ However, it was not until the 1960s that AC gained more general use in the management of acute intoxication. Oral AC effectively prevents the absorption of most drugs present in the stomach at the time of charcoal administration; however, it does not inhibit the absorption of all toxicologically important agents. ${ }^{2)}$

The primary rationale for the use of cathartics together with $\mathrm{AC}$ in the management of acute poisoning is the belief that these agents reduce the absorption of a poison by decreasing the time the poison or the poison-charcoal complex remains in the gut. Also, cathartics have been administered with $\mathrm{AC}$ to reduce the risk of constipation, impaction and quantity of activated charcoal needed, and to improve the taste of AC, thereby reducing its grittiness and making it more palatable. However, not all cathartics achieve this reduction in time and quantity antidotal efficacy of $\mathrm{AC}$ on all poisoning agents. Several in vivo and in vitro studies have shown different cathartics which either produce no significant change in time and quantity of AC necessary for adsorption, give only a modest beneficial effect or even reduce the adsorptive capacity of AC. ${ }^{3-6)}$

Rifampicin is an antibacterial agent used mainly in the treatment of tuberculosis. It is a potent inducer of cytochrome P-450 (CYP) enzymes and thus causes many drug interactions. ${ }^{7)}$ At the usual dose of $600 \mathrm{mg}$ once daily, rifampicin is generally well tolerated, but hepatotoxicity is a potential adverse effect, and several such cases have been reported. ${ }^{8,9)}$

The aim of this study, therefore, was to investigate the effect of sodium chloride and sodium citrate on the in vitro adsorption of therapeutic and simulated toxic doses of rifampicin to AC.

\section{MATERIALS AND METHODS}

Activated charcoal (Ultracarbon, Merck), sodium chloride and sodium citrate (reagent grade) (BDH, England) and rifampicin (IDA, Malta) were used in this study. 50, 100, 200, 400 and $500 \mathrm{mg}$ of AC were placed in test tubes. Several solutions of rifampicin in $2.5,5,10,50$ and $100 \mu \mathrm{g} / \mathrm{ml}$ were prepared in distilled water, and $5 \mathrm{ml}$ of each solution was added to each adsorbent tube. The resulting rifampicin-charcoal slurries were vortex mixed for $30 \mathrm{~s}$, incubated in a water bath shaker for $30 \mathrm{~min}$ at $37^{\circ} \mathrm{C}$, and centrifuged at $3000 \mathrm{rpm}$ for $5 \mathrm{~min}$. Rifampicin was then determined on the clear supernatant using a Jenway Colorimeter 6400 at a wavelength of $320 \mathrm{~nm}$.

Another experiment was carried out to determine the effects of sodium chloride and sodium citrate on the ability of $\mathrm{AC}$ to adsorb rifampicin. $5 \mathrm{ml}$ of solutions containing 7.5 $\mathrm{mg} / \mathrm{ml}$ each of sodium chloride and sodium citrate with 2.5 , $5,10,50$ and $100 \mathrm{mg} / \mathrm{ml}$ rifampicin, prepared using a solution of the cathartics as the solvent for rifampicin, were added to test tubes containing 50,100,200, 400 and $800 \mathrm{mg}$ AC. The tubes were vortex mixed, incubated, centrifuged and analyzed as in the experiment above. In all, duplicate experiments were carried out.

The percentage of rifampicin adsorbed from the original solution was calculated from the percentage of drug remaining in the supernatant. The percentage of drug adsorbed was plotted against the log quantity of adsorbents. The resulting linear plot obtained by regression analysis of the best fitted points was analyzed to determine the quantity of adsorbent which bound $50 \%$ of rifampicin (B-50), as determined by the method of Tallarida and Murray. ${ }^{10)}$

Results were expressed as mean \pm S.E.M. and Student's $t$ test was used to determine the statistical significance. All data were calculated after 6 readings. 


\section{RESULTS}

Table 1 shows the percentage of various concentrations of rifampicin adsorbed to various concentrations of AC. It is evident from this table that increasing the concentration of $\mathrm{AC}$ increases the percent adsorption of rifampicin. Conversely, an increase in the concentration of rifampicin decreases its quantity adsorbed by AC.

The percent adsorption of rifampicin to $\mathrm{AC}$ was significantly $(p<0.05)$ increased by sodium chloride at therapeutic sodium concentrations of 2.5 and $5.0 \mu \mathrm{g} / \mathrm{ml}$ rifampicin (Table 2). At the simulated toxic concentrations (10, 50, and $100 \mu \mathrm{g} / \mathrm{ml}$ ), the adsorption of rifampicin to AC was significantly decreased. Also, the quantity of rifampicin adsorbed decreased with an increasing concentration of rifampicin, but increased with increasing concentration of AC.

The addition of $7.5 \mathrm{mg} / \mathrm{ml}$ sodium citrate significantly $(p<0.05)$ increased the percent adsorption of rifampicin to $\mathrm{AC}$ at both the therapeutic and simulated toxic doses of rifampicin (Table 3). Again, the affinity of AC for rifampicin obeyed quantity-dependent kinetics.

The amounts of AC needed to adsorb $50 \%$ of the therapeutic doses of rifampicin were decreased by sodium chloride, but increased for the simulated toxic doses compared to the control (Figs. 1, 2). The addition of sodium citrate, however,

Table 1. Adsorption of Rifampicin to AC

\begin{tabular}{crrrrc}
\hline \hline \multirow{2}{*}{$\begin{array}{c}\text { Drug } \\
\text { conc. } \\
(\mu \mathrm{g} / \mathrm{ml})\end{array}$} & $50 \mathrm{mg} \mathrm{AC}$ & $100 \mathrm{mg} \mathrm{AC}$ & $200 \mathrm{mg} \mathrm{AC}$ & $400 \mathrm{mg} \mathrm{AC}$ & $800 \mathrm{mg} \mathrm{AC}$ \\
\cline { 2 - 6 } & & & & & \\
\hline 2.5 & $20.10 \pm 8.00$ & $36.40 \pm 8.00$ & $56.40 \pm 2.00$ & 100 & 100 \\
5 & $13.70 \pm 3.52$ & $26.00 \pm 5.00$ & $49.10 \pm 1.50$ & 100 & 100 \\
10 & $6.17 \pm 1.80$ & $14.30 \pm 7.00$ & $30.30 \pm 2.10$ & $61.70 \pm 3.50$ & 100 \\
50 & $2.20 \pm 0.24$ & $4.20 \pm 2.20$ & $9.00 \pm 0.35$ & $19.10 \pm 0.24$ & $39.05 \pm 0.23$ \\
100 & $0.86 \pm 0.14$ & $1.54 \pm 0.24$ & $3.04 \pm 0.06$ & $6.05 \pm 0.11$ & $12.10 \pm 0.12$ \\
\hline
\end{tabular}

Values are expressed as mean \pm S.E.M. $(n=6)$

Table 2. Effect of Sodium Chloride on the Adsorption of Rifampicin to $\mathrm{AC}$

\begin{tabular}{ccrrrc}
\hline \hline \multirow{2}{*}{$\begin{array}{c}\text { Drug } \\
\text { conc. } \\
(\mu \mathrm{g} / \mathrm{ml})\end{array}$} & $50 \mathrm{mg} \mathrm{AC}$ & $100 \mathrm{mg} \mathrm{AC}$ & $200 \mathrm{mg} \mathrm{AC}$ & $400 \mathrm{mg} \mathrm{AC}$ & $800 \mathrm{mg} \mathrm{AC}$ \\
\cline { 2 - 6 } & & & & & \\
\hline 2.5 & $23.90 \pm 2.21$ & $46.90 \pm 3.44$ & $83.80 \pm 2.64$ & 100 & 100 \\
5 & $16.60 \pm 11.02$ & $38.50 \pm 4.30$ & $75.20 \pm 1.60$ & 100 & 100 \\
10 & $6.10 \pm 0.25$ & $13.90 \pm 0.57$ & $26.10 \pm 0.38$ & $54.10 \pm 0.55$ & 100 \\
50 & $1.80 \pm 0.25$ & $3.60 \pm 0.58$ & $7.36 \pm 0.12$ & $12.00 \pm 0.19$ & $24.00 \pm 0.14$ \\
100 & $0.63 \pm 0.11$ & $1.20 \pm 0.20$ & $2.58 \pm 0.03$ & $4.80 \pm 0.07$ & $10.90 \pm 0.27$
\end{tabular}

Values are expressed as mean \pm S.E.M. $(n=6)$.

Table 3. Effect of Sodium Citrate on the Adsorption of Rifampicin to AC

\begin{tabular}{crrrrr}
\hline \hline \multirow{2}{*}{$\begin{array}{c}\text { Drug } \\
\text { conc. } \\
(\mu \mathrm{g} / \mathrm{ml})\end{array}$} & $50 \mathrm{mg} \mathrm{AC}$ & $100 \mathrm{mg} \mathrm{AC}$ & $200 \mathrm{mg} \mathrm{AC}$ & $400 \mathrm{mg} \mathrm{AC}$ & $500 \mathrm{mg} \mathrm{AC}$ \\
\cline { 2 - 6 } & & & & & \\
\hline 2.5 & $36.00 \pm 2.49$ & $72.60 \pm 2.40$ & 100 & 100 & 100 \\
5 & $27.30 \pm 4.50$ & $41.30 \pm 0.54$ & $82.00 \pm 0.94$ & 100 & 100 \\
10 & $10.30 \pm 0.71$ & $19.00 \pm 0.47$ & $35.30 \pm 1.20$ & $74.70 \pm 2.00$ & 100 \\
50 & $2.50 \pm 0.24$ & $5.20 \pm 0.09$ & $10.30 \pm 0.14$ & $26.50 \pm 0.17$ & $42.20 \pm 0.30$ \\
100 & $1.20 \pm 0.07$ & $2.40 \pm 0.14$ & $4.70 \pm 0.07$ & $9.20 \pm 0.14$ & $17.30 \pm 0.31$ \\
\hline
\end{tabular}

Values are expressed as mean \pm S.E.M. $(n=6)$.

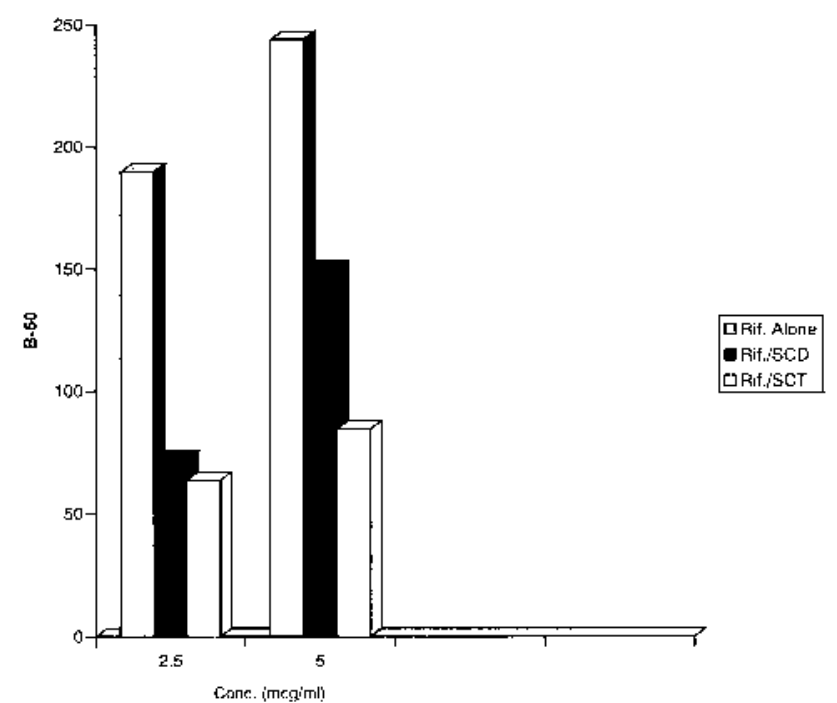

Fig. 1. B-50 Values of Rifampicin in the Presence of SCD and SCT at Therapeutic Doses

Rif. $=$ rifampicin, $\mathrm{SCD}=$ sodium chloride, $\mathrm{SCT}=$ sodium citrate.

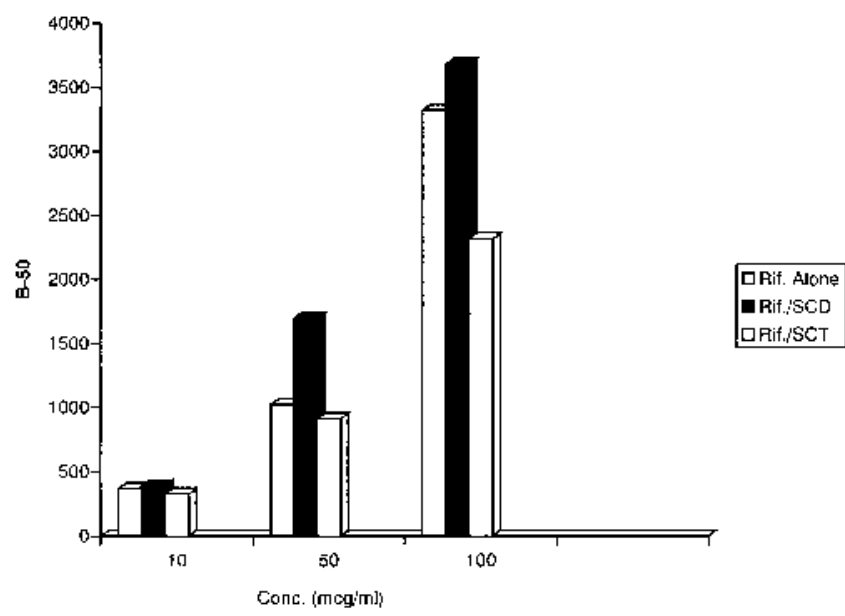

Fig. 2. B-50 Values of Rifampicin in the Presence of SCD and SCT at Simulated Toxic Doses

Rif. $=$ rifampicin, $\mathrm{SCD}=$ sodium chloride, $\mathrm{SCT}=$ sodium citrate.

decreased the quantity of AC needed to adsorb $50 \%$ of both the therapeutic and simulated toxic concentrations of rifampicin compared to both the control and sodium chloride (Figs. 1, 2).

\section{DISCUSSION}

We have investigated the effects of sodium chloride and sodium citrate on the capacity of AC to adsorb rifampicin. Our results showed that the affinity of rifampicin for AC was low. The addition of sodium citrate increased the adsorption at both the therapeutic and simulated toxic doses, leading to a decrease in the B-50 values of rifampicin. However, the addition of sodium chloride decreased the adsorptive capacity of $\mathrm{AC}$ for rifampicin at the simulated toxic doses, resulting in an increase in B-50 values.

AC effectively prevents the absorption of many drugs, but its efficacy is only moderate to poor in certain instances of intoxication. ${ }^{2)}$ Our study indicates that rifampicin has only a 
moderate affinity for $\mathrm{AC}$ in vitro. Based on in vitro and in vivo studies, it has been suggested that with a charcoal: drug ratio of $10: 1$, more than $90 \%$ of most drugs can be adsorbed onto charcoal. ${ }^{2)}$ In vivo studies are needed in this regard to evaluate the charcoal: rifampicin adsorption ratio. In the treatment of drug overdose however, large doses of charcoal are needed to increase the ability of charcoal to come into contact with the toxic substance.

A decrease in B-50 values was noticed when sodium citrate was added to the rifampicin-charcoal slurry; this indicates increased adsorption of rifampicin to AC. Other researchers have observed that citrate ions were responsible for a significant increase in the adsorption of salicylate and oral paraquat to $\mathrm{AC}$. . $^{11,12)}$

The addition of sodium chloride decreased the adsorption of rifampicin to $\mathrm{AC}$, leading to increased $\mathrm{B}-50$ values at the simulated toxic doses. Information on the use of sodium chloride as a cathartic in poison management is scanty. This negative effect on the antidotal efficacy of $\mathrm{AC}$ by sodium chloride could be attributed to the competitive binding of rifampicin and sodium chloride on the charcoal surface. However, since the seemingly competitive binding was insurmountable with the simulated toxic concentrations of rifampicin, it appears that activated charcoal has more affinity for sodium chloride than for rifampicin. It has been suggested that cathartics such as sorbitol, administrated together with AC, could reduce the adsorption capacity of charcoal particles. ${ }^{2)}$ In an in vivo study using a cough syrup which contained, in addition to pholcodine and other compounds, $17.5 \mathrm{~g}$ of sorbitol, the effectiveness of delayed charcoal administration was reduced. ${ }^{13)}$ It is therefore evident that not all cathartics are beneficial in enhancing the antidotal efficacy of $\mathrm{AC}$.

This present study, therefore, does not recommend the concomitant use of $\mathrm{AC}$ and sodium chloride in the treatment of rifampicin overdose. However, the use of sodium citrate with $\mathrm{AC}$ can be beneficial in instances of both therapeutic and simulated toxic doses of rifampicin intoxication. In vivo studies, however, are needed to evaluate these in vitro effects in man.

\section{REFERENCES}

1) Andersen A. H., Acta Pharmacol., 2, 69-78 (1946).

2) Neuvonen P. J., Olkkola K. T., Med. Toxicol., 3, 33-58 (1988).

3) Lapierre G., Algozzine G., Goering P. L., Clin. Toxicol., 18, 793-796 (1981).

4) Akintonwa A., Orisakwe L. O. E., Arch. Int. Pharmacodyn. Ther, 304, 290-294 (1990).

5) Keller R. E., Schwab R. A., Krenzelok E. P., Ann. Emerg. Med., 19, 654-656 (1990).

6) Minton N. A., Henry J. A., J. Toxicol. Clin. Toxicol., 33, 43-49 (1995).

7) Strayhorn V. A., Baciewiez A. M., Self T. H., Arch. Intern. Med., 157, 2453-2458 (1997).

8) Girling D. J., J. Antimicrob. Chemother., 3, 115-132 (1977).

9) Warrington R. J., Hogg G. R., Paraskevas F., Tse K. S., Arch. Intern. Med., 137, 927-930 (1977).

10) Tallarida R. J., Murray R. B., "Manual of Pharmacological Calculations," Springer-Verlag, New York, 1981.

11) Ryan C. F., Spigiel R. W., Zeldes G., Clin. Toxicol., 17, 457-461 (1980).

12) Gaudreault P., Friedman P. A., Lovejoy F. H., Jr., Ann. Emerg. Med., 14, 123-125 (1985).

13) Laine K., Kivisto K. T., Ojala-Karlsson P., Neuvonen P. J., Ther. Drug Monitor, 19, 46-50 (1997). 